\title{
Analysis on the Trade Structural Competitiveness in Manufacturing Industry between Guangzhou and "the Belt and Road" Participating Countries Based on Lafay Index
}

\author{
Xiaofei Luo ${ }^{1}$, Yonghui Han ${ }^{2, a}$, Siqi Zhong ${ }^{3}$ \\ ${ }^{1}$ Faculty of Logistics, Guangdong Mechanical and Electrical Technical College, Guangzhou, Guangdong510515, China \\ ${ }^{2}$ Guangdong Institute for International Strategies, Guangdong University of Foreign Studies, Guangzhou, Guangdong510420, China \\ ${ }^{3}$ Sun Yat-sen University, Guangzhou, Guangdong510275, China
}

\begin{abstract}
The economic development in Guangzhou presents an export-oriented characteristic. Therefore, it is the key path for Guangzhou's manufacturing to upgrade by participating the construction of the Belt and Road initiative. This paper adopts Lafay Index to measure the structural competitiveness of trade between China and countries along the B\&R and finds that Guangzhou has a long-term and stable comparative advantage in clothing and textile industry, metal products industry and leather products industry, but a long-term disadvantage in metal smelting industry, chemical manufacturing industry and non-metallic mineral products. It also shows a high degree of intra-industry trade in food processing industry, sports and entertainment industry.
\end{abstract}

\section{INTRODUCTION}

Over the past 40 years of China's reform and opening up, the industrial restructuring, transformation and upgrading in Guangdong Province, especially the rapid development of Guangzhou manufacturing industry, which continuously integrated into global economy, has brought up a "Guangdong Miracle" (Han et al, 2015)[1]. Guangzhou's GDP climbed to 1.96 trillion Yuan in 2016 from 4.3 billion in 1978, increasing by 455 times. However, Guangzhou as a key city during opening-up, presents an export-oriented characteristic in its economic development, accompanying with a rather strong external dependence, which made it more impacted by international financial crisis (Jiang et al, 2012) [2]. Guangzhou's economy is also entering a critical transformation period, during which there exists excess supply of traditional industries, a lack of impetus for emerging industry and high technology industries, a temporary shortage in industrial development and improper industrial structure. In 2015, the gross output value of manufacturing industry of Guangzhou in 2016 was around 1.63 trillion Yuan, with only a 2\% year-on-year increase, taking $13.8 \%$ of the gross output value of manufacturing industry of Guangdong Province. The manufacturing value added was 400 billion Yuan, growing by $2.2 \%$ from 2014 (figure 1, data from Guangzhou Statistics Bureau).

Though Guangzhou's manufacturing industry is scaling up, the rate of growth has entered a medium-low speed period of steady growth. Under the "new normal", the structure of Guangzhou's manufacturing industry needs to be optimized, and its development model needs to shift to innovation-driven model. Seeking wider cooperation potential is an important channel to urge Guangzhou's development model of manufacturing industry to shift from element-driven and investment-driven to innovation-driven model. The central committee of the CPC has put forward some great ideas as "the Belt and Road" initiative, "Going Global" strategy and Made in China 2025" program, which bring new turning points for Guangzhou's manufacturing industry enhancing its innovative capability. Facing the turning point, Guangzhou was firstly approved the establishment of "Made in China 2025" pilot demonstration cities. The upgrading of Guangzhou's manufacturing industry is imperative. In the mean time, the timely proposal of the "Made in Guangzhou 2025" will lead the direction to the transformation and upgrading of manufacturing in Guangzhou, which will help promote the stable and rapid development of manufacturing capacity and realize the strategic goal of adjusting the industry structure and stabilizing the growth of economy. Based on the background above, it boasts great referential value for promoting production capacity cooperation in Guangzhou to analyse intra-industry trade and comparative advantage in manufacturing industry between Guangzhou and participating countries. 


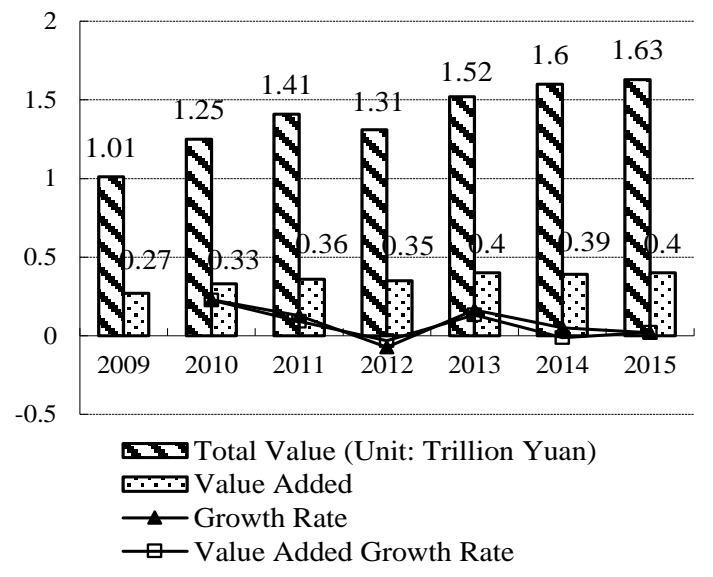

Figure 1. Analysis of the Development of Manufacturing Industry in Guangzhou from 2009 to 2015

\section{Analysis on Trade Structural Competitiveness in Manufacturing Industry}

It is widely accepted in academia to apply RSCA and TC index to analyse the circumstance and tendency of the comparative advantage of inter-regional industries. However, the measurement of RSCA index puts emphasis on inter-industry trade, while fails to excavate information about intra-industry trade. In the sphere of manufacturing industry trade, the contribution from intra-industry trade cannot be ignored. It requires further research about how the comparative advantages of manufacturing industry affect intra-industry and completely reveal the status of comparative advantage of manufacturing industry between Guangzhou and the "B\&R" participating countries. Lafay(1992)[3]brought forward Lafay Index, which simultaneously take trade flows of exports and imports into consideration, superior to traditional RACA index. Furthermore, different from TC index, in Lafay index trade share is weighted based on Normalized Trade Balance (NTB) which consists of classified trade volume and total trade volume. It overcome distortion problem of calculation results owing to economic fluctuation factor (Wu et al, 2012)[4]. Thus this paper uses Zaghini et al.(2005)[5] method for reference and applies Lafay Index to measure the comparative advantage in manufacturing industry between Guangzhou and B\&R participating countries.

\subsection{Lafay Index Construction}

Compared with RCA index, Lafay index can measure the comparative advantage and the intra-trade change in manufacturing sector between Guangzhou and participating countries. The formula is:

$$
L F I_{j}=\frac{100\left[\left(X_{j}-M_{j}\right) /\left(X_{j}+M_{j}\right)-\sum_{j-1}^{N}\left(X_{j}-M_{j}\right) / \sum_{j-1}^{N}\left(X_{j}+M_{j}\right)\right]\left(X_{j}+M_{j}\right)}{\sum_{j-1}^{N}\left(X_{j}+M_{j}\right)}
$$

$X_{j}$ represents the export volumes of the $\mathrm{j}$-th manufacturing sector towards participating countries; $M_{j}$ represents the import volumes of the $\mathrm{j}$-th manufacturing sector towards participating countries; $N$ means total quantity of manufacturing industry. Interpreting $X_{j}$ and $M_{j}$ as the import and export of "the Belt and Road" related industries in Guangzhou, it can reflect the comparative advantage of Guangzhou relative to participating countries. $\left(X_{j}-M_{j}\right) /\left(X_{j}+M_{j}\right)$ in Lafay index means the competitive index of Guangzhou manufacturing sector $\mathrm{j}$ relative to that of participating countries, while $\sum_{j-1}^{N}\left(X_{j}-M_{j}\right) / \sum_{j-1}^{N}\left(X_{j}+M_{j}\right)$ means the competitive index accumulated by all the manufacturing sectors. If these two formulas are subtracted from each other, the result means the extent of deviation of them. $\left(X_{j}+M_{j}\right) / \sum_{j-1}^{N}\left(X_{j}+M_{j}\right)$ means the proportion of the import and export trade volume in the total trade volume between Guangzhou manufacturing sector and participating countries. The more proportion it has, the higher the absolute value of Lafay index in this sector is. It can be judged whether a manufacturing sector has comparative advantage by the positive or negative of Lafay index value. If the value presents to be positive, it means the manufacturing sector has a high degree of specialization and has comparative advantage relative to that in participating countries. Conversely, if the value presents to be negative, it means that the sector has a large import quota and has comparative disadvantage. Lafay index can also reflect the degree of intra-product trade. The further away the value strays from zero, the lower the degree is.

\subsection{Analysis on Comparative Advantage Change in Manufacturing Industry between Guangzhou and B\&R Participating Countries based on Lafay Index}

Using Shang's (2010) [6] method for reference, Guangzhou's manufacturing industry can be divided as 11 sectors, including: (01) food processing, (02) timber processing, (03) metal smelting, (04) chemical products, (05) nonmetallic mineral products, (06) metal products, (07) equipment manufacturing, (08) leather products, (09) clothing and textile, (10) paper printing (11) sports and entertainment. We calculated respectively the Lafay index of Guangzhou's 11 manufacturing sectors relative to those in participating countries. The data sample span from 1995 to 2014. The data comes from WTO Database, World Bank Open Data, Guangzhou Statistical Yearbook and relevant Statistical Bulletin. Table 1 is the result of Lafay index value. The above order numbers of the 11 sectors correspond to the sector numbers in table 1 .

The result shows that in 2014 Lafay index value in (09) clothing and textile industry is the largest. The second largest value appears on (07) equipment manufacturing industry, followed by metal products. While (03) metal smelting industry comes in last. The value of (09) clothing and textile industry in Guangzhou escalated from 1.528 in 1995 to 4.265, with a high degree of the advantages of the division of labor and rapid development. The value of (07) equipment manufacturing industry was 0.057 in 1995 , taking on a 
fluctuant increasing process to 4.283 in 2014. This illustrates that Guangzhou's (07) equipment manufacturing industry and (09) clothing and textile industry not only have revealed comparative advantage, but also play an important role in Guangzhou's manufacturing trade in "the Belt and Road". Besides, the index value of Guangzhou's (03) metal smelting industry is quite low. Though it rises with fluctuation from -6.125 in 1995, it is still -3.151 even in 2014. This explains the import trade volume of Guangzhou's metal smelting industry from participating countries exceeded export trade volume, running a large trade deficit. But the deficit is gradually shrinking. The absolute value of Lafay index of (08) leather products industry, (11) sports and entertainment industry, (01) food processing industry, (02) timber processing industry and (10) paper printing industry are small, closed to zero. This shows a high degree of intra-industry trade between this sectors and participating countries. Because relative to participating countries, these sectors, the ratio of net import and export value to the import and export volume is rather low. Also, the ration of the total value of imports and exports to Guangzhou's import and export volume is relatively low.

Table 1. The Lafay index value of each manufacturing sector in Guangzhou from 1995 to 2014

(a)

\begin{tabular}{|l|l|l|l|l|l|l|}
\hline & $(\mathbf{0 1})$ & $\mathbf{( 0 2 )}$ & $\mathbf{( 0 3 )}$ & $\mathbf{( 0 4 )}$ & $\mathbf{( 0 5 )}$ & $(\mathbf{0 6})$ \\
\hline 1995 & 0.25 & -0.48 & -6.13 & -1.47 & -3.52 & 0.88 \\
\hline 1996 & 0.38 & -0.51 & -6.10 & -1.87 & -3.55 & 1.03 \\
\hline 1997 & 0.15 & -0.64 & -6.24 & -1.95 & -3.49 & 1.15 \\
\hline 1998 & 0.12 & -0.71 & -6.55 & -1.54 & -3.76 & 1.10 \\
\hline 1999 & 0.07 & -0.88 & -6.40 & -2.21 & -3.90 & 1.06 \\
\hline 2000 & 0.13 & -0.77 & -6.24 & -3.31 & -3.35 & 1.05 \\
\hline 2001 & 0.13 & -0.59 & -5.99 & -3.16 & -2.69 & 0.97 \\
\hline 2002 & 0.14 & -0.48 & -5.52 & -2.53 & -2.34 & 1.05 \\
\hline 2003 & 0.04 & -0.40 & -4.98 & -2.84 & -2.52 & 1.06 \\
\hline 2004 & 0.01 & -0.33 & -4.97 & -2.88 & -2.49 & 1.00 \\
\hline 2005 & 0.00 & -0.26 & -4.63 & -2.93 & -2.45 & 1.10 \\
\hline 2006 & 0.20 & -0.20 & -3.60 & -2.77 & -2.89 & 1.09 \\
\hline 2007 & -0.04 & -0.21 & -4.20 & -2.71 & -2.32 & 1.08 \\
\hline 2008 & -0.09 & -0.21 & -4.02 & -3.36 & -1.93 & 0.71 \\
\hline 2009 & -0.13 & -0.23 & -4.04 & -2.85 & -2.68 & 1.61 \\
\hline 2010 & -0.18 & -0.29 & -4.03 & -3.07 & -2.63 & 1.71 \\
\hline 2011 & -0.18 & -0.36 & -3.75 & -3.36 & -2.42 & 1.64 \\
\hline 2012 & -0.21 & -0.37 & -3.65 & -3.22 & -2.81 & 2.13 \\
\hline 2013 & -0.27 & -0.41 & -3.21 & -3.01 & -2.31 & 2.34 \\
\hline 2014 & -0.33 & -0.53 & -3.15 & -3.10 & -2.89 & 2.45 \\
\hline
\end{tabular}

(b)

\begin{tabular}{|l|l|l|l|l|l|}
\hline & $(\mathbf{0 7})$ & $\mathbf{( 0 8 )}$ & $\mathbf{( 0 9 )}$ & $\mathbf{( 1 0 )}$ & $\mathbf{( 1 1 )}$ \\
\hline 1995 & 0.06 & 0.88 & 1.53 & -1.46 & 0.88 \\
\hline 1996 & 0.18 & 0.31 & 1.51 & -1.71 & 0.73 \\
\hline 1997 & 0.62 & 0.43 & 1.50 & -1.83 & 0.69 \\
\hline
\end{tabular}

\begin{tabular}{|l|l|l|l|l|l|}
1998 & 0.53 & 0.53 & 1.61 & -1.85 & 0.52 \\
\hline 1999 & 0.35 & 1.23 & 2.35 & -1.94 & 0.46 \\
\hline 2000 & 0.74 & 0.39 & 2.09 & -1.60 & 0.45 \\
\hline 2001 & 0.83 & 1.34 & 2.52 & -1.38 & 0.48 \\
\hline 2002 & 1.00 & 0.26 & 2.76 & -1.19 & 0.48 \\
\hline 2003 & 1.03 & 0.11 & 2.70 & -1.00 & 0.43 \\
\hline 2004 & 1.43 & 0.67 & 2.76 & -0.82 & 0.14 \\
\hline 2005 & 1.30 & -0.11 & 3.08 & -0.70 & 0.05 \\
\hline 2006 & 1.70 & 0.57 & 2.89 & -0.84 & 0.20 \\
\hline 2007 & 2.43 & 0.97 & 3.55 & -0.48 & 0.00 \\
\hline 2008 & 2.78 & 1.12 & 3.32 & -0.46 & 0.09 \\
\hline 2009 & 3.83 & 0.99 & 3.47 & -0.36 & 0.13 \\
\hline 2010 & 3.93 & 1.12 & 3.52 & -0.41 & 0.12 \\
\hline 2011 & 4.36 & 1.15 & 3.48 & -0.44 & 0.14 \\
\hline 2012 & 4.33 & 1.15 & 4.19 & -0.43 & 0.09 \\
\hline 2013 & 3.81 & 0.73 & 4.06 & -0.35 & 0.11 \\
\hline 2014 & 4.18 & 1.49 & 4.27 & -0.30 & 0.16 \\
\hline
\end{tabular}

Figure 2 is drawn on the data in table 1, intuitively reflecting the time trend and spatial distribution of the Lafay index in each manufacturing sector between Guangzhou and "B\&R" participating countries. As shown in figure 2, clothing and textile industry, equipment manufacturing industry and metal products industry are distant from central axis zero, which explains the degree of intra-industry trade of these three sectors is low, mainly focusing on inter-industry trade. Equipment manufacturing industry and clothing and textile industry score far above the zero-line, which means they have high comparative advantages. While metal smelting industry and nonmetallic mineral products industry are far below the zero-line, meaning their comparative advantages are low. The rising trend of Lafay curve of equipment manufacturing industry shows the comparative advantage of Guangzhou's equipment manufacturing sector is rising. The Lafay curve of chemical products industry has seen a decline, which means its comparative disadvantage is enlarging. The Lafay index curve of Guangzhou's food processing sector and sports and entertainment sector are close to the zero-line, meaning their import and export trade volume is no different than participating countries with a high degree of intra-industry trade. 


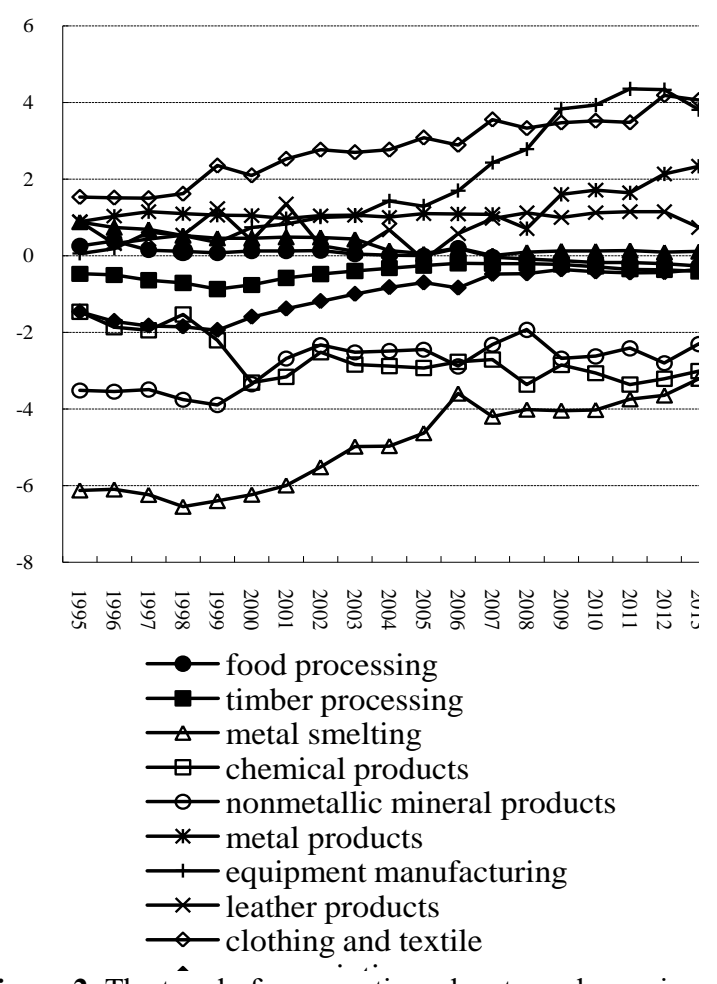

Figure 2. The trend of comparative advantage change in manufacturing industry between Guangzhou and B\&R participating countries from 1995 to 2014

\section{Conclusion and Suggestions}

From the above analysis we can conclude that the comparative advantage of Guangzhou's manufacturing industry focus on equipment manufacturing industry and clothing and textile industry. However, the overall comparative advantage is not sufficient. In fact, the R\&D investment in Guangzhou's manufacturing industry is relatively low, leading to less intellectual property rights and fewer new products. They also have a high degree of homogenization of products. The enterprises show deficiency in key technical reserves and innovation capacity, which leads to a lack of competitive advantage and severely constrains the sustainable development of Guangzhou's manufacturing industry (HE, 2013) [7]. Faced with new opportunities, Guangzhou government should make the corresponding countermeasures on policy arrangement and talent teams building.

Firstly, Guangzhou should make scientific overall development planning about advanced manufacturing industry, drive technology innovations of industrial enterprises and strengthen the support the new industrial format. Concrete steps could include integrating existing special fiscal funds, introducing social capital, setting up development fund, implementing special project such as supporting core-component technical breakthrough, carrier construction and backbone enterprises cultivating in manufacturing industry.

Secondly, Guangzhou government should encourage and guide famous-brand products to register in the international market in time for participating international competition and exploring international market based on certain rewards and subsidies. The government should also encourage existing manufacturing firms to establish standardized manufacture, improve product quality and establish brand reputation.

Lastly, in view of the current situation of a shortage of top talents in manufacturing industry, Guangzhou need to gather a group of high-level personnel with excellent quality and outstanding achievement to settle in Guangzhou. On the one way, this can be achieved through a primary focus on establishing "the Belt and Road" talents communication platform, ensuring that the need of Guangzhou's "going global" strategy and talents in production capacity global cooperation can be met. On the other hand, the government should innovate on talents stimulating mechanism, which is an organic integration of personal interests and business interests, and focus on training science and technology innovative talents.

\section{Acknowledgment}

This work is partially supported by Key Grant Projects of Philosophy and Social Sciences Research, Ministry of Education of China (Grant No.16JZD018). Yonghui Han is the corresponding author, the e-mail is hanyonghui2006@foxmail.com.

\section{References}

1. Y.H. Han, J.H. Zou. Journal of International Trade, 7,108-117(2015)

2. H.Y. Jiang, Q.S. Yang. Economic Geography, 8,78-83(2012)

3. G. Lafay. International Trade Modelling. 209-234(1992)

4. X.B. Wu, J. Chen, Y. Hua. Macroeconomics, 2,42-49(2012)

5. Zaghini. Economics of Transition, 4,629-658(2005)

6. T. Shang. Journal of International Trade, 12,70-77(2010)

7. He Ai, L.C. Lü. Science and Technology Management Research, 22,80-83(2013) 